\title{
ATRP/OMRP/CCT Interplay in Styrene Polymerization Mediated by Iron(II) Complexes: a DFT Study of the $\alpha$-Diimine System
}

\author{
Rinaldo Poli, ${ }^{*[a, b]}$ and Michael P. Shaver ${ }^{[c]}$
}

\begin{abstract}
A DFT study on various model systems has addressed the interference of catalytic chain transfer (CCT) as a function of the $\mathrm{R}^{2}$ substituents in the atom transfer radical polymerization (ATRP) of styrene catalyzed by $\left[\mathrm{FeCl}_{2}\left(\mathrm{R}^{1} \mathrm{~N}=\mathrm{C}\left(\mathrm{R}^{2}\right)-\mathrm{C}\left(\mathrm{R}^{2}\right)=N R^{1}\right)\right]$. All model systems used $R^{1}=\mathrm{CH}_{3}$ in place of the experimental $\mathrm{Cy}$ and $t \mathrm{Bu}$ substituents and 1-phenylethyl in place of the PS chain. A mechanistic investigation of (i) ATRP activation, (ii) radical trapping in OMRP and (iii) pathways leading to the hydride CCT intermediate was conducted with a simplified system with $R^{2}=H$. This study suggests that CCT could occur by direct $\mathrm{H}$-atom transfer without any overbarrier. Further analysis of more realistic models with $\mathrm{R}^{2}=p-$ $\mathrm{C}_{6} \mathrm{H}_{4} \mathrm{~F}$ and $p-\mathrm{C}_{6} \mathrm{H}_{4} \mathrm{NMe}_{2}$ suggests that the electronic effect of the aryl para substituents significantly alters the ATRP activation barrier. Conversely, the $\mathrm{H}$-atom transfer barrier is essentially unaffected. Thus, the greater ATRP catalytic activity of the $p-\mathrm{NMe}_{2}$ system makes the background CCT process less significant. The DFT study also compares the $\left[\mathrm{FeCl}_{2}\left(\mathrm{R}^{1} \mathrm{~N}=\mathrm{C}\left(\mathrm{R}^{2}\right)-\mathrm{C}\left(\mathrm{R}^{2}\right)=N R^{1}\right)\right]$ systems with a diaminobis(phenolato) derivative for which the CCT process shows even greater accessibility but has less incidence because of faster ATRP chain growth and interplay with a more efficient OMRP trapping. The difference between the two systems is attributed to the destabilization of the $\mathrm{Fe}^{\mathrm{ll}}$ catalyst by the geometric constraint of the tetradentate diaminobis(phenolato) ligand.
\end{abstract}

\section{Introduction}

Since its discovery in $1995,{ }^{[1-4]}$ atom transfer radical polymerization (ATRP) has become an intense research area for the assembly of complex, precision-controlled, macromolecular architectures. ${ }^{[5]}$ ATRP depends upon a redox equilibrium between a reduced metal complex, $\mathrm{L} / \mathrm{Mt}^{\mathrm{x}}$ (where $\mathrm{Mt}$ is the metal atom, $L /$ represents the ligand coordination sphere and $x$ is the formal metal oxidation state) and a dormant, halogen-terminated chain, $R_{n}-Y$ in equilibrium with an active radical chain, $R_{n} \cdot$, and the halogenated complex, L/Mt' ${ }^{x+1}-Y$ (Scheme 1, ATRP box). It can be initiated either by mixing the reduced complex and a suitable halogenated compound $R_{0}-Y$ (method A) or by generating the primary radicals $R_{0} \cdot$ from a conventional initiator I in the presence of the oxidized complex (method B, usually

[a] Prof. R. Poli

CNRS, LCC (Laboratoire de Chimie de Coordination)

205 route de Narbonne, BP 44099

F-31077, Toulouse Cedex 4, France

E-mail: rinaldo.poli@lcc-toulouse.fr

[b] Institut Universitaire de France, 103

bd Saint-Michel, 75005, Paris, France

[c] Prof. M. P. Shaver

School of Chemistry, University of Edinburgh

West Mains Road, Edinburgh

EH9 3JJ, United Kingdom

Supporting information for this article is given via a link at the end of the document. called "reverse ATRP"). Following pioneering reports based on copper $^{[1-2]}$ and ruthenium ${ }^{[3-4]}$ complexes, many other metals have been used to control an expansive monomer scope. ${ }^{[6-7]}$

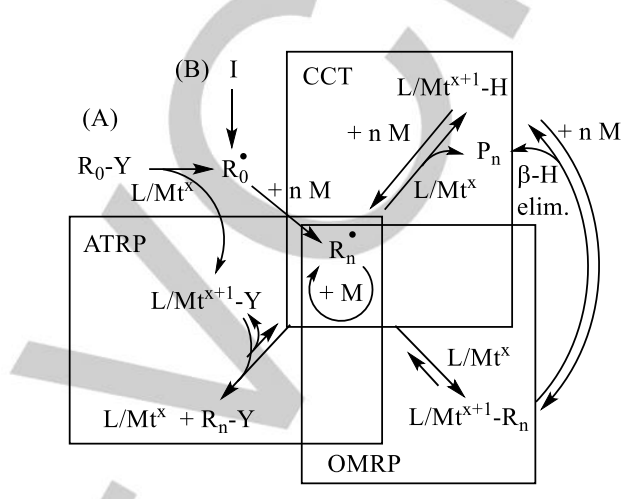

Scheme 1. Interplaying equilibria in metal-mediated radical polymerization (M = monomer).

Subsequent mechanistic studies have revealed a complex interplay of different equilibria, resulting from the various ways in which organic radicals react with transition metal complexes. ${ }^{[8]}$ Two types of reactions are particularly relevant to the catalytic performance of metal complexes in ATRP: radical trapping and chain transfer..$^{\left[{ }^{[]}\right.}$Given that the ATRP equilibrium lies on the side of the reduced complex $\mathrm{L} / \mathrm{Mt}^{\mathrm{x}}$, a significant concentration of the lower oxidation state species is available to directly trap the active radical chain and yield a metal terminated organometallic dormant chain, $\mathrm{L} / \mathrm{Mt}^{\mathrm{x}+1}-\mathrm{R}_{\mathrm{n}}$. This equilibrium is by itself capable of moderating a controlled chain growth in what is now universally known as Organometallic Mediated Radical Polymerization (OMRP, Scheme 1). ${ }^{[9-12]}$ However, the active chain, $R_{n}$, and the reduced complex, $\mathrm{L} / \mathrm{Mt}^{\mathrm{x}}$, may also engage in an $\mathrm{H}$ atom transfer from a $\beta \mathrm{C}-\mathrm{H}$ bond to the metal, yielding a dead macromolecule with an unsaturated chain end, $\mathrm{P}_{\mathrm{n}}$, and a hydride complex, $\mathrm{L} / \mathrm{Mt}^{\mathrm{x}+1}-\mathrm{H}$, which can initiate a new chain upon $\mathrm{H}$ atom transfer to monomer. This phenomenon is called Catalytic Chain Transfer (CCT, Scheme 1). Interplay of these three reaction pathways was demonstrated for a Mo system ${ }^{[13-15]}$ and other metal complexes have subsequently revealed an ATRP/OMRP interplay, comprising osmium, ${ }^{[16-17]}$ chromium, ${ }^{[18-20]}$ vanadium ${ }^{[21}$ 22] and iron. ${ }^{[23]}$

Iron is now attracting growing attention as an abundant, inexpensive and biocompatible element. ${ }^{[24]}$ ATRP catalyzed by iron complexes, first introduced in 1997, ${ }^{[25]}$ has become a very active area of research. One remarkable system is $\left[\mathrm{FeCl}_{2}(\alpha-\right.$ diimine)] where $\alpha$-diimine $=R^{1} \mathrm{~N}=\mathrm{C}\left(\mathrm{R}^{2}\right) \mathrm{C}\left(\mathrm{R}^{2}\right)=N R^{1}$ (see Scheme 2), applied by Gibson and co-workers to the polymerisation of styrene and acrylate monomers. ${ }^{[26-28]}$ This system acts as catalyst for controlled chain growth when $R^{2}=H$, whereas complexes with $\mathrm{R}^{2}=$ aryl lead, in general, to polymers with lowmolecular weights that do not increase with conversion, indicating CCT. ${ }^{[26-28]}$ This phenomenon was interpreted as 
resulting from a competing trapping of the growing radical chain by the excess $\mathrm{Fe}^{\mathrm{ll}}$ catalyst, leading to an organometallic Fe ${ }^{\text {III }}$ dormant chain through the OMRP equilibrium. However, instead of contributing to a better control in chain growth this OMRP trapping process was proposed to open access to CCT via a $\beta-\mathrm{H}$ elimination process, as shown in Scheme 1. ${ }^{[29]}$ This represented a new twist in the interplay of various reactivity pathways in metal-mediated radical polymerization.<smiles>[R]C1=C([R])N([R1])[Z6](Cl)N1[R]</smiles>

Scheme 2. The $\left[\mathrm{FeCl}_{2}(\alpha\right.$-dimine) $]$ type ATRP catalyst.

There are several points of interest in this peculiar system that have attracted our attention and stimulated a more thorough computational analysis. A key point is the suggestion that the OMRP trapping was an intermediate in a $\beta-\mathrm{H}$ elimination sequence towards $\mathrm{CCT}$, as opposed to direct $\mathrm{H}$ atom transfer. There was, however, no direct proof because stable alkyliron(III) complexes could not be isolated for this system. Also important is the peculiar role of the $R^{2}$ group in opening access to this CCT pathway as opposed to controlled growth by ATRP. In particular, a correlation was highlighted between the polymerization outcome and the spin state of the $\left[\mathrm{FeCl}_{3}\right.$ ( $\alpha$-diimine)] complex: well controlled polymerization by ATRP occurs for complexes that were found to adopt a high spin ground state while polymerization is affected by CCT for complexes for which an intermediate spin ground state was suggested by solution magnetic measurements. Finally, it is interesting to compare this system with other Fe complexes that do not lead to any significant interference of CCT, notably a recently developed diaminebis(phenolato) complex. ${ }^{[30]}$ We have recently presented a computational investigation of the latter system, although restricted to the ATRP and OMRP equilibria. ${ }^{[31]}$ In the present contribution, we report a thorough analysis of the $\left[\mathrm{FeCl}_{2}(\alpha-\right.$ diimine)] system and compare the ability of this system with the diaminebis(phenolato)iron(II) complex to access the CCT pathway. As a final introductory note, it is relevant to mention that another computational study by Johansson and Swart recently addressed this system. ${ }^{[32]}$ That study, though using a high level of theory, was based on the rather imaginative and experimentally unsubstantiated proposition that the OMRP dormant species is generated by direct abstraction of the alkyl group from the ATRP dormant species $\mathrm{R}_{\mathrm{n}} \mathrm{Cl}$, leaving behind a free chlorine atom. This is at striking disagreement with the established mechanism of Scheme 1 and with conventional wisdom originating from old investigations of the one-electron oxidative addition of alkyl halides to transition metal complexes. ${ }^{[3-34]}$ The authors also did not explicitly address how the CCT process would occur starting from the organometallic complex, limiting the relevance of their conclusions.

\section{Results and Discussion}

The reactions of interest for understanding this system involve four distinct iron complexes: the 4-coordinate $\left[\mathrm{FeCl}_{2}\right.$ (a-diimine)] ATRP catalyst $\left(1^{\mathrm{x}}\right.$, Scheme 3 , corresponding to $\mathrm{L} / \mathrm{Mt}^{\mathrm{x}}$ in Scheme $1)$, the 5-coordinate ATRP radical trapping species $\left[\mathrm{FeCl}_{3}(\alpha-\right.$ diimine)] $\left(\mathbf{2}^{\mathbf{x}}\right)$, the 5-coordinate OMRP dormant species $\left[\mathrm{FeCl}_{2} \mathrm{R}_{\mathrm{n}}(\alpha\right.$-diimine $\left.)\right]\left(3^{\mathrm{x}}\right)$, and the 5-coordinate CCT intermediate $\left[\mathrm{FeCl}_{2} \mathrm{H}\right.$ ( $\alpha$-diimine $\left.)\right]\left(4^{\mathrm{x}}\right)$. The monomer of reference for our investigation is styrene. For the purpose of the calculations, the chain $R_{n}$ was simplified to a 1-phenylethyl group (namely, the entire chain prior to the last monomer unit was replaced by an $\mathrm{H}$ atom). A variability of spin states is to be expected.

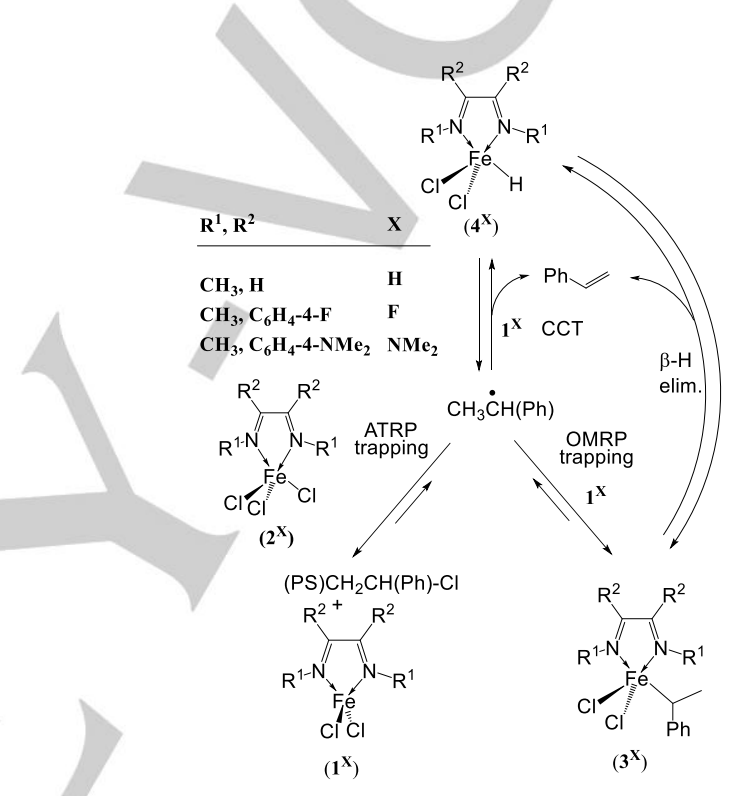

Scheme 3. Complexes analyzed in this study.

The $\left[\mathrm{FeCl}_{2}\right.$ ( $\alpha$-diimine)] compounds are known ${ }^{[35]}$ to adopt a high spin state $(S=2)$. Also, in spite of the notorious redox noninnocent behaviour of the a-diimine ligands, this system was shown to comprise a neutral dimine ligand and a high-spin Fe(II) metal center, so other possible electronic distribution have not been considered. ${ }^{\left[{ }^{[6]}\right.}$ The related $\left[\mathrm{FeCl}_{3}\right.$ ( $\alpha$-diimine)] complexes with $R^{2}=H$ were suggested to adopt a high spin state $(S=5 / 2)$ when $R^{1}$ is an alkyl group and an intermediate spin state $(S=$ $3 / 2$ ) when $R^{1}=$ aryl, from magnetic susceptibility measurements using Evans' NMR method. ${ }^{[28]}$ Complexes with $\mathrm{R}^{2}=$ aryl and $\mathrm{R}^{1}$ $=$ alkyl $(t B u, C y)$ were also of intermediate spin state, except for $\mathrm{C}_{6} \mathrm{H}_{4}-4-\mathrm{NMe}_{2}$ which was again high spin. ${ }^{[35]}$ Further work characterizing these $\left[\mathrm{FeCl}_{3}\right.$ ( $\alpha$-diimine)] complexes with SQUID, $X$-ray, EPR and Mössbauer studies was not published: these studies supported the different spin state assignments, but were complicated and did not allow for unambiguous conclusions. ${ }^{[37]}$ The spin state of the OMRP dormant species is unknown, since this species or model compounds having the same stoichiometry could not be isolated or observed spectroscopically or magnetically in situ. The same holds for the putative CCT 
hydride intermediate. To carry out our investigation, we have selected the B3PW91* functional, a modified version of the B3PW91 functional with a reduced contribution of exact HartreeFock exchange, because it proved ideal for the investigation of

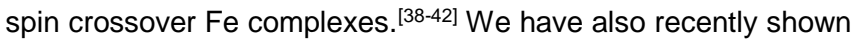
that this functional reproduces the correct ground state of known alkyl(porphyrin)iron(III) compounds. ${ }^{[31]}$ We did not consider it necessary to further benchmark different functionals, since this has already been done by us $^{[31]}$ and others ${ }^{[32]}$ on similar systems. We have however applied an empirical dispersion correction to the energy data using Grimme's D3 method, ${ }^{[43]}$ since the use of a dispersion approach was shown essential when analyzing bond dissociation processes. ${ }^{[44]}$ The results presented in this contribution confirm that the dispersion correction has important consequences for processes associated with the establishment of new interactions (whether these are van der Waals or real bonds) while the effect on the energy gap between different spin isomers is small.

We first modeled the complete mechanistic interplay (ATRP/OMRP/CCT/ $\beta-H$ elimination) with a simplified ligand in which $\mathrm{R}^{1}=\mathrm{CH}_{3}$ and $\mathrm{R}^{2}=\mathrm{H}$, yielding systems $\mathbf{1}^{\mathrm{H}}, \mathbf{2}^{\mathrm{H}}, \mathbf{3}^{\mathrm{H}}$ and $4^{\mathrm{H}}$ (Scheme 3). While in the experimental system $\mathrm{R}^{1}=t \mathrm{Bu}$ or $\mathrm{Cy}$ promote a well controlled ATRP process, ${ }^{[28]}$ the smaller $\mathrm{CH}_{3}$ groups gives optimal computational efficiency and minimal alteration of electronic properties. We later explore the ligand influence on the polymerization behavior with selected calculations on (i) a ligand that leads to chain growth with little or no contamination of CCT $\left(\mathrm{R}^{2}=\mathrm{C}_{6} \mathrm{H}_{4}-4-\mathrm{NMe}_{2}\right)\left(\mathbf{X}=\mathbf{N M e _ { 2 }}\right)$, and (ii) a representative ligand leading to extensive CCT $\left(\mathrm{R}^{2}=\mathrm{C}_{6} \mathrm{H}_{4}^{-}\right.$ $4-F ; \mathbf{X}=\mathbf{F}$ ). For both ligands, the bulky $\mathrm{R}^{1}$ group was again reduced to the simpler $\mathrm{CH}_{3}$. All calculations were carried out at the full QM level.

\section{(a) The $X=H$ system.}

The results for the 4-coordinate $\mathrm{Fe}^{\text {ll }}$ dichloride complex ( $\mathrm{S}=$ 2) are shown in Table 1 and Figure 1a. The closest chemically related experimental structure is that of compound $\left[\mathrm{FeCl}_{2}(\mathrm{CyN}=\mathrm{CH}-\mathrm{CH}=\mathrm{NCy})\right]$, ${ }^{[26]}$ the geometric parameters of which are also reported in Table 1 for comparison. The match of the bond distances is quite good, whereas the angles deviate substantially, but this may be related to packing phenomena as the crystal habit imposes $\mathrm{C}_{2 v}$ symmetry to the $\mathrm{N}$-cyclohexyl derivative. The optimization without any symmetry constraint, on the other hand, led to a nearly $\mathrm{C}_{\mathrm{s}}$-symmetric geometry with two sets of significantly different $\mathrm{Cl}-\mathrm{Fe}-\mathrm{N}$ angles and a visible folding of the 5-membered $\mathrm{FeN}_{2} \mathrm{C}_{2}$ ring at the $\mathrm{N}-\mathrm{N}$ hinge. Indeed, the structure of compound $\left[\mathrm{FeCl}_{2}(\mathrm{CyN}=\mathrm{CPh}-\mathrm{CPh}=\mathrm{NCy})\right]$, with a crystallographically imposed $\mathrm{C}_{\mathrm{s}}$ symmetry, ${ }^{[35]}$ shows a similar distortion and parameters, also shown in Table 1, that are much closer to those optimized for $\mathbf{1}^{\mathrm{H}}$. An important contrast is also apparent when comparing the optimized geometry of $1^{\mathrm{H}}$ with that recently described for the $\left[\mathrm{Fe}\left(\mathrm{Me}_{2} \mathrm{NCH}_{2} \mathrm{CH}_{2} \mathrm{~N}\left(\mathrm{CH}_{2}-6-\mathrm{C}_{6} \mathrm{H}_{2}-2\right.\right.\right.$,4$\left.\mathrm{Cl}_{2}-\mathrm{O}\right)_{2}$ ] derivative, henceforth abbreviated as [Fe(DABP)] (Figure 1b).[31] The DABP ligand, because of the constraint of the 6-membered rings formed upon coordination of the phenolato $\mathrm{O}$ donor and the amine $\mathrm{N}$ donor, forces the geometry to significantly deviate from the preferred tetrahedral environment; this is evidenced by the wider angle between the bonds to the two $\mathrm{O}$ donor atoms $\left(\mathrm{O}-\mathrm{Fe}-\mathrm{O}, 144.5^{\circ}\right)$ relative to the two unconstrained $\mathrm{Fe}-\mathrm{Cl}$ bonds in $\mathbf{1}^{\mathrm{H}}$. Additional ring tension is therefore to be expected in the $[\mathrm{Fe}(\mathrm{DABP})]$ derivative, relative to the less constrained geometry observed for $1^{\mathrm{H}}$.

Table 1. Relevant geometric parameters of DFT-optimized quintet $\mathbf{I}^{\mathbf{H}}$ and comparison with the experimental structures of $\left[\mathrm{FeCl}_{2}(\mathrm{CyN}=\mathrm{CR}-\mathrm{CR}=\mathrm{NCy})\right](\mathrm{R}=$ $\mathrm{H}^{[26]} \mathrm{Ph}^{[35]}$.

\begin{tabular}{llll}
\hline Parameters $^{[a]}$ & DFT & X-ray $^{[26]}$ & X-ray $^{[35]}$ \\
\hline $\mathrm{Fe}-\mathrm{Cl}$ & $2.202,2.229$ & $2.231(2)$ & $2.2551(16), 2.2183(15)$ \\
$\mathrm{Fe}-\mathrm{N}$ & $2.058,2.058$ & $2.125(4)$ & $2.077(3)$ \\
$\mathrm{Cl}-\mathrm{Fe}-\mathrm{Cl}$ & 127.4 & $120.08(10)$ & $125.62(7)$ \\
$\mathrm{N}-\mathrm{Fe}-\mathrm{N}$ & 80.4 & $78.0(2)$ & $78.42^{\mathrm{b}}$ \\
$\mathrm{Cl}-\mathrm{Fe}-\mathrm{N}$ & $102.4,102.4$, & $111.13(11)$ & $101.79(9), 119.24(9)$ \\
\hline
\end{tabular}

[a] Distances in $\AA$, angles in ${ }^{\circ}$. [b] This value was obtained without e.s.d. from the CSD deposited structure, since the value reported in the original publication is erroneous.

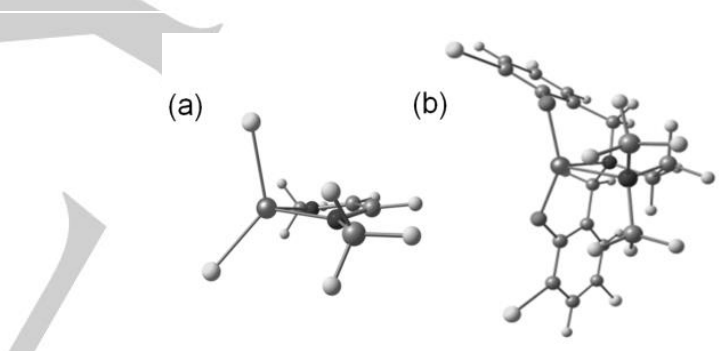

Figure 1. View of the optimized geometries of $\mathrm{I}^{\mathrm{H}}$ (a) and comparison with that optimized for $[\mathrm{Fe}(\mathrm{DABP})]^{[31]}(\mathrm{b})$.

System $2^{\mathrm{H}}$ was investigated in the sextet and quartet states, the first one corresponding to the known ground state. The calculations (optimized geometrical parameters, relative energy and structure in Table 2 and Figure 2) agree with the experiment and the effect of the dispersion correction (B3PW91*-D3, see Computational Details) on the sextet-quartet gap is minor. The converged sextet geometry, ${ }^{6} \mathbf{2}^{\mathrm{H}}$, is close to a trigonal bipyramid (tbp) with axial $\mathrm{Cl}$ and diimine $\mathrm{N}$ donor, although slightly distorted by the small bite angle of the diimine ligand. This geometry corresponds to that experimentally determined for the related $\left[\mathrm{FeCl}_{3}(t \mathrm{BuN}=\mathrm{CH}-\mathrm{CH}=\mathrm{NtBu})\right],{ }^{[35]}$ with a good match of the structural parameters. The optimized quartet geometry, ${ }^{4} \mathbf{2}^{\mathrm{H}}$, on the other hand, has a much wider $\mathrm{Cl}(\mathrm{eq})-\mathrm{Fe}-\mathrm{Cl}(\mathrm{eq})$ angle and appears closer to a square pyramid. This geometrical change can be conveniently monitored by the well known $\tau$ parameter, ${ }^{[45]}$ see Table 2. The $\mathrm{Fe}-\mathrm{Cl}$ distances in ${ }^{6} \mathbf{2}^{\mathbf{H}}$ and ${ }^{4} \mathbf{2}^{\mathrm{H}}$ are similar, whereas the Fe-N distances are much shorter in ${ }^{4} \mathbf{2}^{\mathrm{H}}$, presumably because an electron is placed in an orbital with metalligand antibonding character in ${ }^{6} 2^{\mathrm{H}}$. The higher energy of ${ }^{4} \mathbf{2}^{\mathrm{H}}$ indicates that the electron pairing cost is greater than the additional bond-related stabilization. Figure 2 also presents a 
comparison with the optimized geometry for the related DABP complex. For this pseudo-tbp Fe ${ }^{\text {III }}$ system, the DABP ligand adapts well to the coordination environment, with similar bond angles to those of the less constrained diimine system. For instance, the $\mathrm{O}-\mathrm{Fe}-\mathrm{O}$ angle $\left(128.1^{\circ}\right)$ is close to the optimized unconstrained $\mathrm{Cl}-\mathrm{Fe}-\mathrm{Cl}$ system in ${ }^{6} \mathbf{2}^{\mathrm{H}}$.

When including the energy of the models for the radical chain, $\mathrm{PhCH}\left(\mathrm{CH}_{3}\right)$, and the ATRP dormant chain, $\mathrm{PhCH}(\mathrm{Cl}) \mathrm{CH}_{3}$, the calculated energy change associated to the ATRP equilibrium, $\Delta \mathrm{E}(\mathrm{ATRP})$, is $20.6 \mathrm{kcal} / \mathrm{mol}$ (Equation 1). The dispersion correction slightly lowered this value to $17.9 \mathrm{kcal} / \mathrm{mol}$. The effect of the dispersion correction is small here due to the competing $\mathrm{C}-\mathrm{Cl}$ bond breaking and $\mathrm{Fe}-\mathrm{Cl}$ bond making.

Table 2. Relevant geometric parameters of DFT-optimized $2^{\mathbf{H}}$ and comparison with the experimental structure of $\left[\mathrm{FeCl}_{2}(\mathrm{tBuN}=\mathrm{CH}-\mathrm{CH}=\mathrm{N} t \mathrm{Bu})\right]^{[35]}$.

\begin{tabular}{llll}
\hline Parameters ${ }^{\text {[a] }}$ & ${ }^{6} \mathbf{2}^{\mathrm{H}}(\mathrm{DFT})$ & ${ }^{4} \mathbf{2}^{\mathrm{H}}(\mathrm{DFT})$ & $\begin{array}{l}\mathbf{F F e C l}_{3}(\mathrm{tBuN}=\mathrm{CH}- \\
\mathbf{C H}=\mathrm{N}(\mathrm{Bu})](\mathrm{X}-\mathrm{ray})\end{array}$ \\
\hline $\mathrm{Fe}-\mathrm{Cl}(\mathrm{ax})$ & 2.234 & 2.195 & $2.285(3), 2.294(3)$ \\
$\mathrm{Fe}-\mathrm{Cl}(\mathrm{eq})$ & $2.227,2.227$ & $2.222,2.222$ & $2.2053(19), 2.2109(19)$ \\
$\mathrm{Fe}-\mathrm{N}(\mathrm{ax})$ & 2.274 & 2.008 & $2.243(7), 2.275(7)$ \\
$\mathrm{Fe}-\mathrm{N}(\mathrm{eq})$ & 2.192 & 2.132 & $2.145(6), 2.141(6)$ \\
$\mathrm{Cl}(\mathrm{ax})-\mathrm{Fe}-\mathrm{Cl}(\mathrm{eq})$ & $102.1,102.1$ & $95.3,95.3$ & $94.13(6), 94.68(7)$ \\
$\mathrm{Cl}(\mathrm{eq})-\mathrm{Fe}-\mathrm{Cl}(\mathrm{eq})$ & 121.4 & 151.9 & $127.08(14), 122.69(13)$ \\
$\mathrm{N}-\mathrm{Fe}-\mathrm{N}$ & 73.4 & 79.2 & $77.2(2), 77.7(2)$ \\
$\mathrm{Cl}(\mathrm{ax})-\mathrm{Fe}-\mathrm{N}(\mathrm{ax})$ & 164.7 & 178.0 & $177.83(19), 176.4(2)$ \\
$\tau$ & 0.722 & 0.435 & $0.846,0.895$ \\
\hline
\end{tabular}

[a] Distances in $\AA$, angles in ${ }^{\circ}, \Delta \mathrm{E}\left(\mathrm{B} 3 \mathrm{PW} 91^{*}\right.$ ) in $\mathrm{kcal} / \mathrm{mol}$ (with B3PW91*-D3 in parentheses). [b] From ref. [35]. The crystal structure features two independent molecules in the asymmetric unit.

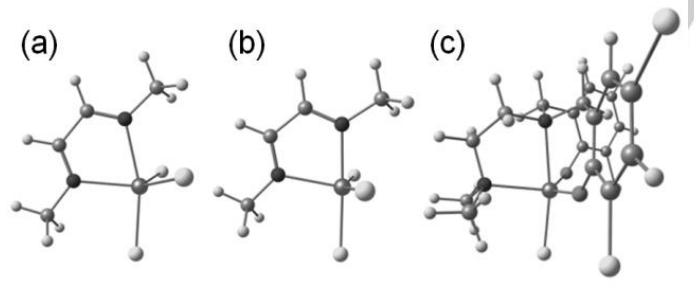

Figure 2. Views of the optimized geometries of ${ }^{6} \mathbf{2}^{\mathrm{H}}(\mathrm{a}),{ }^{4} \mathbf{2}^{\mathrm{H}}$ (b), and of the previously optimized sextet $\left[\mathrm{FeCl}\left(\mathrm{Me}_{2} \mathrm{NCH}_{2} \mathrm{CH}_{2} \mathrm{~N}\left(\mathrm{CH}_{2}-6-\mathrm{C}_{6} \mathrm{H}_{2}-2,4-\mathrm{Cl}_{2}-\mathrm{O}\right)_{2}\right]^{[31]}\right.$ (c).

$$
\mathbf{1}+\mathrm{PhCH}(\mathrm{Cl}) \mathrm{CH}_{3} \underset{k_{\mathrm{da}}}{\stackrel{k_{\mathrm{a}}}{\longrightarrow}} \mathbf{2}+\mathrm{Ph}_{\mathrm{C}}^{\stackrel{\leftrightarrow}{\longrightarrow}} \mathrm{HCH}_{3}
$$

We can compare this result with that of the related $[\mathrm{Fe}(\mathrm{DABP})]$ complex. ${ }^{[31]}$ In that case, $\triangle \mathrm{E}(\mathrm{ATRP})$ is much smaller, only $7.2 \mathrm{kcal} / \mathrm{mol}$ calculated at the same level of theory, consistent with the experimental evidence of a much faster polymerization rate. While the two systems are isoelectronic, moving from a neutral 4-coordinate quintet $\mathrm{Fe}^{\text {ll }}$ complex to a neutral 5-coordinate sextet Fe $\mathrm{Fe}^{\text {III }}$ complex, the geometric constraint imposed by the DABP ligand is more adaptable to the tbp environment of $\mathrm{Fe}^{\mathrm{III}}$ than to the tetrahedral environment of $\mathrm{Fe}^{\mathrm{ll}}$, inducing a ground state destabilization of the Fe" complex, a resulting decrease of the ATRP activation energy and faster observed polymerization rates.

Table 3. Relevant geometric parameters of DFT-optimized $\mathbf{5}$ and $\mathbf{3}$

\begin{tabular}{|c|c|c|c|c|}
\hline & & 5 & & 3 \\
\hline Parameters ${ }^{[a]}$ & 65 & 45 & 25 & ${ }^{43}$ \\
\hline $\mathrm{Fe}-\mathrm{C}$ & 2.062 & 2.009 & 1.957 & 2.211 \\
\hline $\mathrm{Fe}-\mathrm{Cl}$ & $2.250,2.250$ & $\begin{array}{l}2.239 \\
2.239\end{array}$ & $2.225,2.226$ & $\begin{array}{l}2.268 \\
2.287\end{array}$ \\
\hline $\mathrm{Fe}-\mathrm{N}(\mathrm{ax})$ & 2.310 & 2.130 & 2.055 & 2.173 \\
\hline $\mathrm{Fe}-\mathrm{N}(\mathrm{eq})$ & 2.270 & 2.148 & 1.899 & 2.200 \\
\hline $\mathrm{Cl}-\mathrm{Fe}-\mathrm{Cl}$ & 121.3 & 148.3 & 151.2 & 162.6 \\
\hline $\mathrm{N}-\mathrm{Fe}-\mathrm{N}$ & 71.4 & 77.3 & 80.5 & 76.1 \\
\hline $\mathrm{C}-\mathrm{Fe}-\mathrm{Cl}$ & $102.0,102.0$ & $91.9,91.9$ & $91.7,91.7$ & $92.1,92.3$ \\
\hline C-Fe-N(ax) & 161.7 & 178.0 & 177.7 & 172.9 \\
\hline$\tau$ & 0.672 & 0.495 & 0.442 & 0.172 \\
\hline$\Delta \mathrm{E}$ & $8.4(8.5)$ & $0.0(0.0)$ & $14.6(13.4)$ & \\
\hline
\end{tabular}

[a] Distances in $\AA$, angles in ${ }^{\circ}, \Delta \mathrm{E}\left(\mathrm{B} 3 \mathrm{PW} 91^{*}\right.$ ) in $\mathrm{kcal} / \mathrm{mol}$ (with B3PW91*-D3 in parentheses).

For the OMRP dormant species $3^{\mathbf{H}}$, we first optimized geometries using a further simplified model, where the Febonded alkyl group was replaced with $\mathrm{CH}_{3}(\mathbf{5})$, pursuing all possible spin states: high $(S=5 / 2)$, intermediate $(S=3 / 2)$ and low $(S=1 / 2)$ (results in Table 3 and Figure 3$)$. Alkyl(porphyrin)iron(III) complexes, adopting a square pyramidal geometry with apical alkyl group, exist in either the high or low spin state. ${ }^{[4]}$ On the other hand, the recently analyzed DABP system was calculated to have an intermediate spin ground state. ${ }^{[31]}$ The calculations on $\mathbf{5}$ also indicate an intermediate spin ground state, with the $\mathrm{CH}_{3}$ group occupying one axial site of the pseudo-tbp geometry. An isomeric structure with the alkyl group in a pseudo-equatorial position is higher in energy (details in SI), whereas ${ }^{6} 5$ and ${ }^{2} 5$ are respectively 8.4 and $14.6 \mathrm{kcal} / \mathrm{mol}$ higher, with the empirical dispersion correction having only a small effect on the energy gaps, as in $2^{\mathrm{H}}$. Note that the geometrical parameters of ${ }^{6} 5$ and ${ }^{4} 5$ are similar to those of the corresponding trichloride systems ${ }^{6} \mathbf{2}^{\mathrm{H}}$ and ${ }^{\mathbf{4}} \mathbf{2}^{\mathrm{H}}$ (cf. Table 2 and Figure 2). The equatorial-equatorial $\mathrm{Cl}-\mathrm{Fe}-\mathrm{Cl}$ angle further widens in ${ }^{2} \mathbf{5}$, making this structure closer to a square pyramid as suggested by the $\tau$ parameter. The stronger ligand field imparted by the alkyl group makes it preferable to optimize the bond interaction at the cost of pairing two electrons from the sextet to the quartet. However, pairing two additional electrons on going from ${ }^{4} 5$ to ${ }^{2} 5$ is 
unfavorable with no more bond stabilization to be gained, as the only antibonding electron is removed on going from ${ }^{6} 5$ to ${ }^{4} 5$.
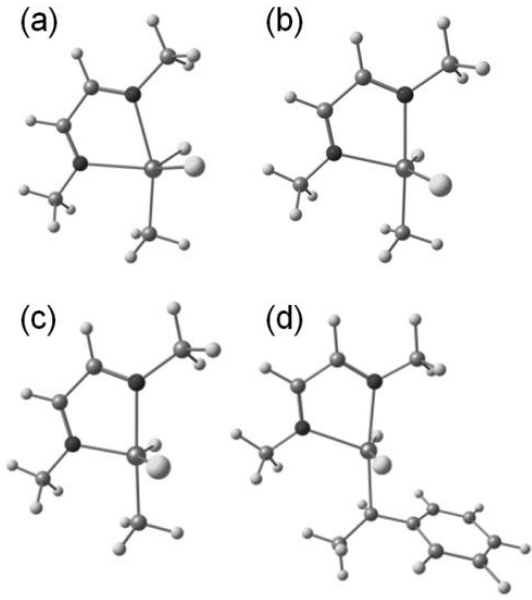

Figure 3. Views of the optimized geometries of 65 (a), ${ }^{45}$ (b) ${ }^{25}$ (c) and ${ }^{4} 3^{\mathrm{H}}$

On the basis of the above results, the 1-phenylethyl derivative $3^{\mathrm{H}}$ was optimized in the quartet state. The results are also shown in Table 3 and Figure 3, together with those of the simpler model. There are several striking differences between the geometries of ${ }^{4} 5$ and ${ }^{4} 3^{\mathbf{H}}$. A first and most important difference is the Fe-C distance, which is ca. $0.2 \AA$ longer in ${ }^{4} 3^{\mathrm{H}}$. This may be somewhat expected, since the $\mathrm{CH}_{3}$ radical is more reactive than the $\mathrm{Ph}\left(\mathrm{CH}_{3}\right) \mathrm{CH}$ radical and can therefore establish a stronger bond with the Fe center. However, such a large difference is surprising and indicates a very weak interaction. Indeed, the OMRP equilibrium (Equation 2) is calculated to provide a very small stabilization: $\triangle \mathrm{E}(\mathrm{OMRP})=1.0 \mathrm{kcal} / \mathrm{mol}$ at the B3PW91* level. When dispersion forces were taken into account, however, this stabilisation increased substantially to yield a BDE of $14.5 \mathrm{kcal} / \mathrm{mol}$ at the B3PW91*-D3 level. An even larger effect was found for the corresponding DABP system, where $\triangle \mathrm{E}(\mathrm{OMRP})$ increased by $17.7 \mathrm{kcal} / \mathrm{mol}$ from 9.4 $\left(\mathrm{B} 3 \mathrm{PW} 91^{*}\right)$ to 27.1 (B3PW91*-D3) $\mathrm{kcal} / \mathrm{mol}^{\left[{ }^{[31]}\right.}$ This result parallels the effect of the dispersion correction previously calculated for the $\mathrm{Co}-\mathrm{CH}_{3}$ in cobalamin. ${ }^{[44]}$

III

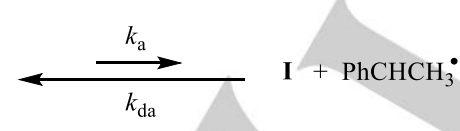

The observed energy trend, both in terms of absolute values before and after the dispersion correction, suggests a significantly weaker $\mathrm{Fe}-\mathrm{C}$ bond in ${ }^{4} 3^{\mathrm{H}}$ than in the corresponding DABP system. The interpretation of this difference is the same offered above for the ATRP equilibrium: the ring strain destabilization of the Fe" complex by the DABP ligand. Hence, while the DABP system may provide a dual ATRP/OMRP control in styrene polymerization, ${ }^{[30]}$ the calculations suggest that OMRP provides a smaller moderating effect for the diimine system. We remark that the $\mathrm{T} \Delta \mathrm{S}(\mathrm{OMRP})$ term will render $\triangle \mathrm{G}(\mathrm{OMRP})$ numerically smaller. In addition, application of the dispersion correction to interactions established in condensed phases from gas-phase calculations may lead to an overestimation of the bond strength (vide infra) ${ }^{[47-48]}$ Incidentally, the generation of ${ }^{4} 3^{H}$ plus a $\mathrm{Cl}$ atom from $1^{\mathrm{H}}$ and $\mathrm{PhCH}(\mathrm{Cl}) \mathrm{CH}_{3}$, as suggested in Johansson and Swart's previous work, ${ }^{[32]}$ has a cost of 56.2 $\mathrm{kcal} / \mathrm{mol}$. This confirms both a fault in their model system as well as the established notion ${ }^{[34]}$ that a metal complex can abstract a halogen atom from an alkyl halide to leave the carbon based radical, rather than the other way around.

The $\mathrm{CH}_{3}$ carbon atom in ${ }^{4} 5$ is more pyramidalized (sum of the three $\mathrm{H}-\mathrm{C}-\mathrm{H}$ angles $=338.9^{\circ}$ ) than the 1 -phenylethyl carbon atom in ${ }^{4} 3^{\mathrm{H}}$ (sum of the three relevant bond angles $=346.3^{\circ}$ ). The Mulliken spin density is 3.34 for $\mathrm{Fe}$ and -0.34 for $\mathrm{C}$ in the methyl derivative ${ }^{4} 5$, whereas it is 3.44 for $F e$ and -0.53 for $C$ in the 1-phenylethyl derivative ${ }^{4} 3^{\mathrm{H}}$. These data further support the much weaker bond resulting from the antiparallel spin interaction between the $\mathrm{S}=2 \mathrm{Fe}^{\mathrm{Il}}$ complex $\mathbf{1}^{\mathrm{H}}$ and the 1-phenylethyl radical. A curious difference between the optimized ${ }^{4} 5$ and ${ }^{4} 3^{H}$ geometries is the significantly wider $\mathrm{Cl}-\mathrm{Fe}-\mathrm{Cl}$ angle in the latter, even wider than in ${ }^{2} 5$. This phenomenon may be the consequence of a steric repulsion with the phenyl ring.

Table 4. Relevant geometric parameters of DFT-optimized $\mathbf{4}^{\mathrm{H}}$

\begin{tabular}{llll}
\hline Parameters ${ }^{\mathrm{a}]}$ & $\mathbf{6} \mathbf{4}^{\mathrm{H}}$ & $\mathbf{4} \mathbf{4}^{\mathrm{H}}$ & $\mathbf{2} \mathbf{H}^{\mathrm{H}}$ \\
\hline $\mathrm{Fe}-\mathrm{H}$ & 1.677 & 1.508 & 1.488 \\
$\mathrm{Fe}-\mathrm{Cl}$ & $2.224,2.227$ & $2.207,2.207$ & $2.187,2.188$ \\
$\mathrm{Fe}-\mathrm{N}(\mathrm{ax})$ & 2.251 & 2.126 & 2.050 \\
$\mathrm{Fe}-\mathrm{N}(\mathrm{eq})$ & 2.254 & 2.139 & 1.852 \\
$\mathrm{Cl}-\mathrm{Fe}-\mathrm{Cl}$ & 121.3 & 152.9 & 155.7 \\
$\mathrm{H}-\mathrm{Fe}-\mathrm{N}(\mathrm{ax})$ & 152.0 & 178.3 & 178.7 \\
$\mathrm{~N}-\mathrm{Fe}-\mathrm{N}$ & 72.1 & 77.7 & 81.4 \\
$\mathrm{Cl}-\mathrm{Fe}-\mathrm{N}(\mathrm{eq})$ & $115.8,120.3$ & $103.5,103.6$ & $102.1,102.1$ \\
\hline$\Delta \mathrm{E}$ & $\mathbf{2 . 3 ( 2 . 3 )}$ & $\mathbf{0 . 0}(\mathbf{0 . 0})$ & $\mathbf{1 4 . 2 ( 1 3 . 0 )}$ \\
\hline
\end{tabular}

[a] Distances in $\AA$, angles in ${ }^{\circ}, \Delta \mathrm{E}\left(\mathrm{B} 3 \mathrm{PW} 91^{*}\right.$ ) in $\mathrm{kcal} / \mathrm{mol}$ (with B3PW91*-D3 in parentheses). [b] From ref. [35]. The crystal structure features two independent molecules in the asymmetric unit.

Of greater interest, however, is the mechanism of $\mathrm{H}$ atom transfer leading to the hydride system $4^{\mathrm{H}}$. We investigated both direct $\mathrm{H}$ atom transfer from the radical to $\mathbf{1}^{\mathrm{H}}$ and trapping to $3^{\mathrm{H}}$ followed by $\beta-\mathrm{H}$ elimination. Before exploring the two possible pathways, we present the structure and relative energy of the $4^{\mathrm{H}}$ intermediate. Given the similar ligand field strength of $\mathrm{H}$ and alkyl ligands, $4^{\mathrm{H}}$ was expected to display similar spin ground state and structure as 5 . Indeed, ${ }^{4} 4^{\mathrm{H}}$ is more stable than ${ }^{6} \mathbf{4}^{\mathbf{H}}$ but by $2.3 \mathrm{kcal} / \mathrm{mol}$ only, while ${ }^{2} 4^{\mathrm{H}}$ is much higher (Table 4 , Figure 4 ). The same basic features of $\mathbf{5}$ systems are also noticeable here: $\mathrm{Fe}-\mathrm{N}$ bond shortening and $\mathrm{Cl}-\mathrm{Fe}-\mathrm{Cl}$ angle widening on going from ${ }^{6} 4^{\mathrm{H}}$ to ${ }^{4} 4^{\mathrm{H}}$. Relative to the combination of the $\mathrm{Fe}^{\text {Il }}$ complex 
$1^{\mathrm{H}}$ and the 1-phenylethyl radical, the reaction leading to ${ }^{4} 4^{\mathrm{H}}$ and styrene (equation 3 ) is uphill: $\Delta \mathrm{E}(\mathrm{CCT})=27.1$ (B3PW61*) or 25.6 (B3PW91*-D3) $\mathrm{kcal} / \mathrm{mol}$. Here again, the dispersion correction is small given the bond breaking and making. This energy makes the process relatively accessible for thermal reactivity, provided there is no unusually large kinetic barrier.
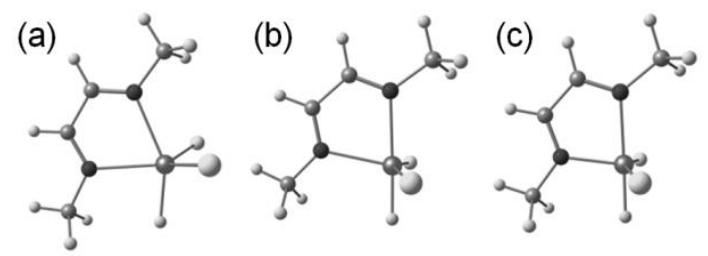

Figure 4. Views of the optimized geometries of ${ }^{6 I V H}(a),{ }^{4} \mathbf{I V}^{\mathbf{H}}$ (b) and ${ }^{2} \mathbf{V}^{\mathbf{H}}$ (c)

$$
\mathbf{I}+\mathrm{Ph}_{\mathrm{C} H C H} \stackrel{k_{\mathrm{H}}}{\stackrel{\stackrel{k_{-H}}{\longrightarrow}}{\longrightarrow}} \quad \text { IV }+\mathrm{CH}_{2}=\mathrm{CHPh}
$$

The direct pathway was probed by a partial optimization scan, starting from the combination of ${ }^{4} 4^{\mathrm{H}}$ and styrene and gradually decreasing the $\mathrm{C} \cdots \mathrm{H}$ distance. The resulting energy trend is shown in Figure 5. At the B3PW91* level, the approach of the radical to compound $1^{\mathrm{H}}$ goes through a shallow local minimum at slightly lower energy than the sum of the two separate products, corresponding to a loose van der Waals adduct between ${ }^{4} 4^{\mathrm{H}}$ and styrene (stabilization energy of 2.6 $\mathrm{kcal} / \mathrm{mol}$ ). In this optimized geometry (Figure 5) the styrene molecule is essentially planar and unperturbed relative to the isolated styrene molecule, with a long distance of $3.379 \AA$ between the $\mathrm{CH}_{2}$ carbon atom and the $\mathrm{H}$ atom of ${ }^{4} 4^{\mathrm{H}}$. The stabilization of this adduct appears to be insured by a $\mathrm{C}-\mathrm{H}-\pi \mathrm{H}$ bond between the $\mathrm{C}-\mathrm{H}$ bond of one imine $\mathrm{N}-\mathrm{CH}_{3}$ group and the $\mathrm{C} 1-\mathrm{C} 2$ bond of the benzene ring at distances of 2.831 and 2.985 $\AA$. The $\mathrm{H}$ transfer pathway from this adduct to the sum of $\mathbf{1}^{\mathrm{H}}$ and $\mathrm{PhMeCH}^{\cdot}$ involves a very small energy increase until a $\mathrm{C} . . \mathrm{H}$ distance of $2 \AA$, then dropping drastically at shorter distances. We were unable to find the $\mathrm{H}$ atom transfer saddle point in this flat region of the PES. The highest energy point $\left({ }^{4} \mathbf{T S} \mathbf{S}_{\mathrm{H}}\right)$ corresponds to a $\mathrm{C} \cdots \mathrm{H}$ distance of $2 \AA$ and is still lower than the separate reagents. Application of the dispersion correction shifts substantially the reaction coordinate toward lower energy and makes the shallow energy maximum disappear completely (Figure 5, square marks), yielding a completely barrierless $\mathrm{H}$ atom transfer. Thus, the reverse process accessing ${ }^{4} 4^{\mathrm{H}}$ with elimination of styrene occurs without any overbarrier, suggesting that this process would occur directly, without the need of radical addition to the metal center.

Before proceeding with an exploration of alternative pathways, it is relevant to briefly comment on the application of dispersion corrections to the estimation of very weak van der Waals interactions. The binding energy of two species coming together is overestimated when gas-phase calculations are used to describe real systems in a condensed phase. The correction does not take into account the fact that each component is losing stabilizing dispersive interactions with its environment.
This situation is only partially attenuated by inclusion of a polarizable continuum model. Note that in Figure 5 all systems are greatly stabilized when the D3 correction is taken into account, except the initial and final systems which correspond to the sum of two separate molecules. A more appropriate description of this system would only be possible by calculations of larger systems with the explicit inclusion of many solvent molecules, which is not trivial. This phenomenon equally affects the estimation of stronger interactions, such as the above discussed Fe-C bond dissociation energy in the OMRP dormant species 3. The utility of a dispersion correction in the case of associative transition states that are characterized by a very small interaction energy is therefore questionable. In addition, the contribution of the $\mathrm{T} \Delta \mathrm{S}$ term to the barrier of an associative process occurring in a condensed phase is also difficult to estimate from gas-phase or polarizable continuum calculations. ${ }^{[49-52]}$ Therefore, the present analysis will only focus on the relative difference of the electronic energy barriers for different processes, considering that the dispersion and $T \Delta S$ effects will contribute more or less equally if the geometries of the different transition states are very similar.

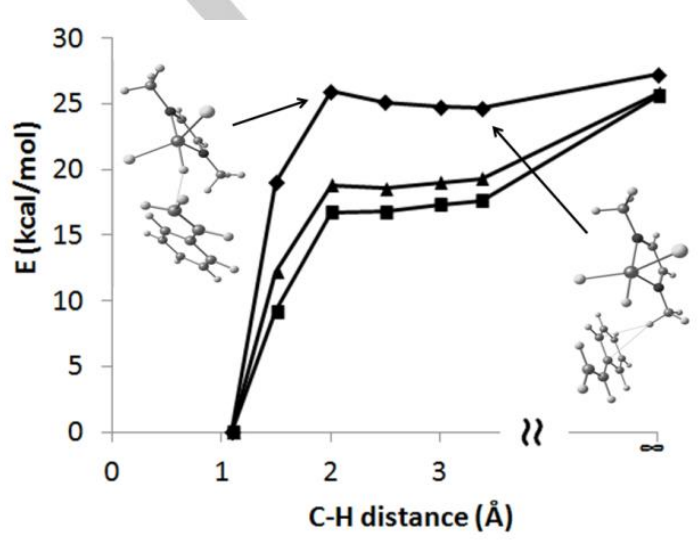

Figure 5. Relative energy changes (diamonds: B3PW91*; squares: B3PW91* D3; triangles: B3PW $91^{*}$-D3 further corrected by a PCM in styrene, see Computational details) along the direct $\mathrm{H}$ atom transfer pathway of $\mathrm{CCT}$ for compound $\mathrm{IH}^{\mathrm{H}}$.

The reaction coordinate of the $\beta-\mathrm{H}$ elimination leading from ${ }^{4} 3^{\mathrm{H}}$ to ${ }^{4} 4^{\mathrm{H}}$ was also explored in order to establish whether this process may also be an independent source of CCT, as previously proposed. ${ }^{[28]}$ If the TS of this process is at higher energy than that of the direct $\mathrm{H}$-atom transfer process, then ${ }^{4} 3^{\mathrm{H}}$ would only play the role of an off-loop species rather than an intermediate of the CCT cycle. The typical $\beta-\mathrm{H}$ elimination pathway requires an empty coordination site in a cis position relative to the alkyl group, which is the case for ${ }^{4} 3^{\mathrm{H}}$. However, it also likely requires an empty metal orbital, which is not available in ${ }^{4} 3^{\mathrm{H}}$ but it is in ${ }^{2} 3^{\mathrm{H}}$, in order to stabilize the olefin binding in the resulting 17-electron olefin-hydride intermediate (Scheme 4). We have therefore considered the possibility that the $\beta-\mathrm{H}$ elimination reaction is a two-state reaction, with a spin crossover to a ${ }^{2} 3^{\mathrm{H}}$ intermediate. This is energetically possible: the doublet state for the simpler 5 system is only $14.6(13.4) \mathrm{kcal} / \mathrm{mol}$ above the 
quartet state, an energy difference smaller than that required to reach the CCT hydride intermediate ${ }^{4} \mathbf{4}^{\mathrm{H}}$.

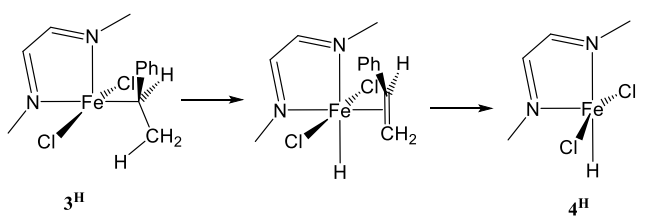

Scheme 4. Typical $\beta-\mathrm{H}$ elimination pathway, idealized for the $\mathrm{Fe}$ III complex $3^{\mathrm{H}}$.

Table 5. Relevant geometric parameters of DFT-optimized molecules along the $\beta-\mathrm{H}$ elimination pathway from ${ }^{2} 3^{\mathrm{H}}$

\begin{tabular}{|c|c|c|c|c|}
\hline Parameters ${ }^{[a]}$ & ${ }^{2 / 4} \mathrm{MECP}_{1}$ & ${ }^{2} 3^{H}$ & ${ }^{2 / 4} \mathrm{MECP}_{2}$ & ${ }^{4} \mathbf{T S}_{\beta}$ \\
\hline $\mathrm{Fe}-\mathrm{C}$ & 2.005 & 2.003 & 2.399 & 2.429 \\
\hline $\mathrm{C}-\mathrm{C}$ & 1.510 & 1.509 & 1.376 & 1.386 \\
\hline $\mathrm{Fe} \cdots \mathrm{H}$ & 1.871 & 1.824 & 1.504 & 1.538 \\
\hline $\mathrm{C} \cdots \mathrm{H}$ & 1.141 & 1.146 & 2.089 & 1.874 \\
\hline $\mathrm{Fe}-\mathrm{Cl}$ & $2.267,2.280$ & $\begin{array}{l}2.261 \\
2.278\end{array}$ & $2.280,2.300$ & $\begin{array}{l}2.346 \\
2.323\end{array}$ \\
\hline $\mathrm{Fe}-\mathrm{N}(\mathrm{ax})$ & 2.082 & 2.064 & 2.012 & 2.145 \\
\hline $\mathrm{Fe}-\mathrm{N}(\mathrm{eq})$ & 1.916 & 1.904 & 2.086 & 2.111 \\
\hline $\mathrm{Cl}-\mathrm{Fe}-\mathrm{Cl}$ & 166.2 & 168.7 & 172.3 & 169.8 \\
\hline C-Fe-N(ax) & 170.9 & 168.7 & 171.0 & 172.9 \\
\hline $\mathrm{N}-\mathrm{Fe}-\mathrm{N}$ & 80.0 & 80.4 & 79.2 & 77.7 \\
\hline $\mathrm{Cl}-\mathrm{Fe}-\mathrm{N}(\mathrm{eq})$ & $94.0,94.7$ & $92.8,93.5$ & $91.9,92.9$ & $91.4,93.3$ \\
\hline $\mathrm{Fe}-\mathrm{C}-\mathrm{C}$ & 80.7 & 79.2 & 68.0 & 69.6 \\
\hline$\Delta \mathrm{E}$ & $8.4(8.5)$ & $0.0(0.0)$ & $14.6(13.4)$ & \\
\hline
\end{tabular}

[a] Distances in $\AA$, angles in ${ }^{\circ}, \Delta \mathrm{E}\left(\mathrm{B} 3 \mathrm{PW} 91^{*}\right.$ ) in $\mathrm{kcal} / \mathrm{mol}$ (with B3PW91*-D3 in parentheses) (relative to $\mathrm{I}^{\mathrm{H}}+1$-phenylethyl radical).

The OMRP dormant species was thus also optimized in the doublet state, ${ }^{2} \mathbf{3}^{\mathrm{H}}$ (Table 5, Figure 6). The energy of ${ }^{2} \mathbf{3}^{\mathrm{H}}$ is 14.9 $\mathrm{kcal} / \mathrm{mol}$ higher than $\mathbf{1}^{\mathrm{H}}+\mathrm{PhMeCH}^{*}$ at the $\mathrm{B} 3 \mathrm{PW} 91^{*}$ level $(0.3$ $\mathrm{kcal} / \mathrm{mol}$ higher at the B3PW91*-D3 level). Recall that ${ }^{4} 3^{\mathrm{H}}$ was calculated to be stabilized relative to the separate $1^{\mathrm{H}}+\mathrm{PhMeCH}^{*}$ (equation 2; B3PW91*: $-1.0 \mathrm{kcal} / \mathrm{mol}$; B3PW91*-D3: -14.5 $\mathrm{kcal} / \mathrm{mol})$. In other words, ${ }^{2} 3^{\mathrm{H}}$ is higher in energy relative to ${ }^{4} 3^{\mathrm{H}}$ by 15.9 (B3PW91*) or 14.8 (B3PW91*-D3) $\mathrm{kcal} / \mathrm{mol}$. Interestingly, while ${ }^{4} 3^{\mathrm{H}}$ features the phenyl group of the alkyl substituent facing the metal empty site, this position is occupied by the $\mathrm{CH}_{3}$ group in ${ }^{2} 3^{\mathrm{H}}$ and an agostic interaction exists between the Fe center and one $\mathrm{C}-\mathrm{H}$ bond, as indicated by the $\mathrm{C}$ $\mathrm{H}$ bond elongation and the narrow Fe-C-C angle, see Table 5 .

The MECP leading from ${ }^{4} 3^{\mathrm{H}}$ to ${ }^{2} \mathbf{3}^{\mathrm{H}}\left({ }^{2 / 4} \mathbf{M E C P} \mathbf{P}_{1}\right)$ was also optimized, yielding a slightly higher energy than ${ }^{2} 3^{\mathrm{H}}$ and $\mathrm{a}$ geometry quite close to it, with only a slightly longer $\mathrm{Fe} \cdots \mathrm{H}$ contact, a slightly less elongated $\mathrm{C}-\mathrm{H}$ bond, and a marginally wider Fe-C-C angle. Next, we attempted the optimization of a doublet hydride-styrene complex as pictured in Scheme 4. However, this optimization failed to give a stable minimum, leading back to the geometry of ${ }^{2} 3^{\mathrm{H}}$ instead. The instability of this postulated intermediate is not so surprising: there are no known examples of stable $\pi$-complexes of $\mathrm{Fe}^{\text {IIII }}$ with olefin ligands. Stabilization of metal-olefin bonds is highly dependent on efficient back-bonding from low oxidation state metal centers. Hence, olefin elimination from ${ }^{2} 3^{\mathrm{H}}$ requires simultaneous $\beta-\mathrm{H}$ transfer to the metal and olefin expulsion.
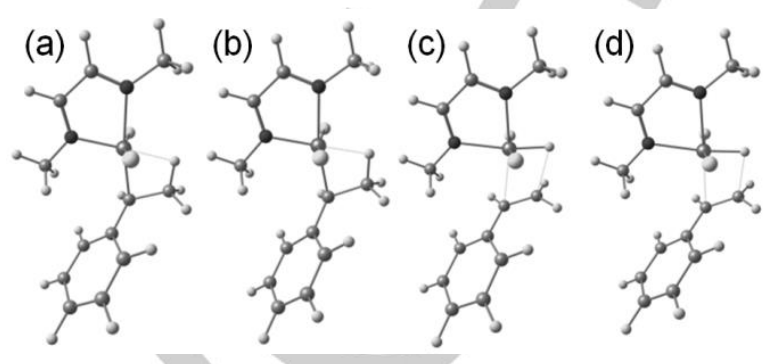

Figure 6. Views of critical geometries along the $\beta-\mathrm{H}$ elimination pathway: (a) ${ }^{2 / 4} \mathbf{M E C P}_{1}$ between ${ }^{4} 3^{\mathrm{H}}$ and ${ }^{2} 3^{\mathrm{H}}$; (b) ${ }^{2} 3^{\mathrm{H}}$; (c) ${ }^{2 / 4} \mathrm{MECP}_{2}$ between ${ }^{2} 3^{\mathrm{H}}$ and ${ }^{4} 4^{\mathrm{H}}+$ styrene; (d) ${ }^{4} \mathrm{TS}_{\beta}$ between ${ }^{4} 3^{\mathrm{H}}$ and ${ }^{4} 4^{\mathrm{H}}+$ styrene.

The coordinate leading from ${ }^{2} 3^{H}$ to the hydride CCT intermediate ${ }^{4} 4^{\mathrm{H}}$ requires a second MECP. This point $\left({ }^{2 / 4} \mathbf{M E C P}_{2}\right)$ was located by B3PW31* $4.0 \mathrm{kcal} / \mathrm{mol}$ above ${ }^{4} 4^{\mathrm{H}}$ as shown in Figure 6 and Table 5. Note that the D3 correction moves the energy of this system below that of the separate reagents. The $\mathrm{Fe}-\mathrm{H}$ bond at this crossing point is already fully formed according to the distance (cf. Table 4 and Table 5) while the Fe$\mathrm{C}$ bond is still relatively short at $2.399 \AA, 0.4 \AA$ longer than in ${ }^{2} 3^{\mathrm{H}}$ but only ca. $0.2 \AA$ longer than in ${ }^{4} 3^{\mathrm{H}}$. The styrene molecule has already gained significant $\mathrm{C}=\mathrm{C}$ double bond character and is close to planarity. ${ }^{2 / 4} \mathrm{MECP}_{2}$ constitutes the rate limiting point along this two-state pathway and its electronic energy makes this pathway less favorable relative to the direct $\mathrm{H}$ atom transfer.

While olefin coordination does not yield a stable intermediate along the elimination pathway, it is possible to envisage a single state $\beta-\mathrm{H}$ elimination pathway along the quartet PES, without crossing over to ${ }^{2} 3^{\mathrm{H}}$. We have also explored this possibility and indeed found a quartet transition state, ${ }^{4} \mathbf{T} \mathbf{S}_{\beta}$, very close in energy to the ${ }^{4} 4^{\mathrm{H}}$ product (only $0.4 \mathrm{kcal} / \mathrm{mol}$ higher in terms of B3PW91* electronic energy). The geometry of this TS (shown in Figure 6 and Table 5) features similar parameters to those of ${ }^{2 / 4} \mathrm{MECP}_{2}$, with slightly longer $\mathrm{Fe}-\mathrm{C}, \mathrm{C}-\mathrm{C}$ and $\mathrm{Fe}-\mathrm{H}$ and shorter $\mathrm{C} \cdots \mathrm{H}$ distances. Since ${ }^{4} \mathbf{T S}_{\boldsymbol{\beta}}$ is lower in energy than ${ }^{2 / 4} \mathbf{M E C P} \mathbf{P}_{2}$, the single state $\beta-\mathrm{H}$ elimination pathway via ${ }^{4} \mathrm{TS}_{\beta}$ appears preferred over the two-state pathway via ${ }^{2 / 4} \mathbf{M E C P}$, with ${ }^{2} 3^{\mathrm{H}}$ as a steady state off loop species. Nonetheless, this $\beta-\mathrm{H}$ elimination overbarrier, relative to the ${ }^{4} 4^{\mathrm{H}}$ product, is small $(0.4 \mathrm{kcal} / \mathrm{mol})$ but not zero in terms of pure B3PW91* electronic energy.

As argued above, given the various computational uncertainties, we shall limit our considerations on the competitive CCT pathways to the electronic energies. The three calculated pathways: (i) direct $\mathrm{H}$ atom transfer via ${ }^{4} \mathbf{T S}_{\mathbf{H}}$; (ii) single state (quartet) $\beta-\mathrm{H}$ elimination from the OMRP dormant 
species via ${ }^{4} \mathbf{T S}_{\beta}$; and (iii) two-state $\beta$-H elimination via ${ }^{2 / 4} \mathbf{M E C P}_{\mathbf{1}}$, ${ }^{2} 3^{\mathrm{H}}$ and ${ }^{2 / 4} \mathbf{M E C P}_{2}$; are summarized in Figure 7. All alternative rate-limiting structures, ${ }^{4} \mathbf{T S}_{\mathbf{H}},{ }^{4} \mathbf{T S}_{\beta}$ and ${ }^{2 / 4} \mathbf{M E C P}_{2}$, consist of a loose adduct between the two reaction products, the hydride complex ${ }^{4} 4^{\mathrm{H}}$ and styrene. We conclude that CCT primarily occurs via direct $\beta-\mathrm{H}$ atom transfer via ${ }^{4} \mathrm{TS}_{\mathrm{H}}$, with a possible contribution from $\beta-\mathrm{H}$ elimination via the OMRP dormant state ${ }^{4} 3^{\mathrm{H}}$, without the need to crossover to the doublet PES.

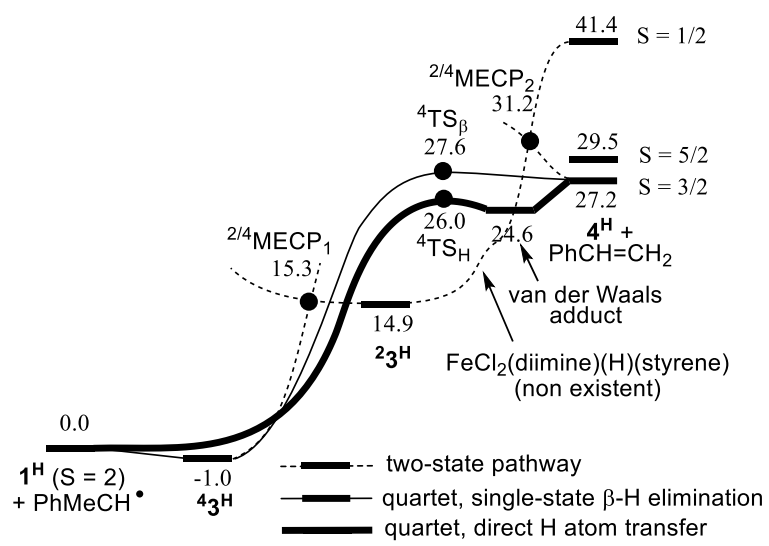

Figure 7. Reaction coordinates for the CCT process from $\mathbf{I H}^{\mathrm{H}}$ and 1-phenylethyl radical (relative energies are in $\mathrm{kcal} / \mathrm{mol}$ calculated on the gas phase systems at the B3PW91* level without dispersion correction, see text).

\section{(b) The $\mathrm{X}=\mathrm{NMe}_{2}$ and $\mathrm{F}$ systems.}

Given the larger size of these systems, calculations were restricted to the key local minima $1^{x}, 2^{x}, 3^{x}$, and $4^{x}$. The optimized geometries of $1^{\mathrm{F}}$ and $1^{\mathrm{NMe} 2}$ closely parallel that already discussed above for the simpler $1^{\mathrm{H}}$ model, with a folded ring at the $\mathrm{N}-\mathrm{N}$ hinge and optimized parameters close to those experimentally determined for the $\mathrm{N}$-Cy substituted compounds (see Supporting Information). ${ }^{[35]}$ The effect of the spin state of the $\mathrm{Fe}^{\text {IIII }}$ trichloride derivative 2 on the polymerization behavior (controlled chain growth vs. CCT) is important, so the structures of $2^{\mathrm{F}}$ and $\mathbf{2}^{\mathrm{NMe} 2}$ were optimized, like $\mathbf{2}^{\mathrm{H}}$, in the sextet and quartet states. The only reported $\mathrm{X}$-ray structure for a $\left[\mathrm{FeCl}_{3}\right.$ ( $\alpha$-diimine)] compound is that of $\left[\mathrm{FeCl}_{3}(t \mathrm{BuN}=\mathrm{CH}-\mathrm{CH}=\mathrm{N} t \mathrm{Bu})\right]$ (cf. Table 2) with a sextet ground state. Indeed, the structural parameters of this molecule are close to those optimized for ${ }^{6} 2^{\mathrm{F}}$ and ${ }^{6} \mathbf{2}^{\mathrm{NMe}}$, whereas those for optimized ${ }^{4} 2^{\mathrm{F}}$ and ${ }^{4} \mathbf{2}^{\mathrm{NMe} 2}$ are, like those of ${ }^{4} \mathbf{2}^{\mathrm{H}}$, different with significantly shorter $\mathrm{Fe}-\mathrm{N}$ bond lengths and a wider $\mathrm{Cl}(\mathrm{eq})-\mathrm{Fe}-\mathrm{Cl}(\mathrm{eq})$ angle (see SI). In terms of relative stability, the $\mathrm{B} 3 \mathrm{PW} 91^{*}$ calculations predict a sextet ground state for both compounds, the quartet state being higher by an amount independent on the nature of $X(11.0 \mathrm{kcal} / \mathrm{mol}, 10.1 \mathrm{kcal} / \mathrm{mol}$ after dispersion correction). The same conclusion was reported by Johansson and Swart using different functionals. ${ }^{[32]}$ The interference of CCT into the ATRP process may therefore have another explanation not correlated to spin state. Taking the $\mathrm{PhMeCHCl}$ and $\mathrm{PhMeCH}^{\circ}$ energies and the dispersion correction into account, equation 1 yields $\triangle \mathrm{E}(\mathrm{ATRP})=18.4$ $\mathrm{kcal} / \mathrm{mol}(\mathrm{X}=\mathrm{F})$ and $16.6 \mathrm{kcal} / \mathrm{mol}\left(\mathrm{X}=\mathrm{NMe}_{2}\right)$. The difference as a function of $X$ may be attributed to the electronic effect of the phenyl substituent, the more electron-withdrawing $\mathrm{F}$ atom making it harder to add an electronegative $\mathrm{Cl}$ atom to the $\mathrm{Fe}$ center. This leads to the prediction of a faster polymerization for the $\mathrm{NMe}_{2}$ derivative, which agrees with the experimental evidence. ${ }^{[35]}$ The two systems are compared in Figure 8.

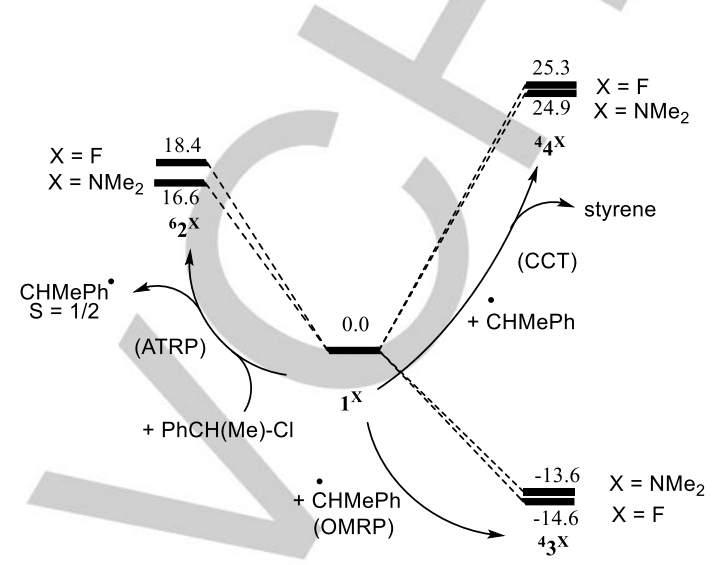

Figure 8. Energy diagram of the interplaying processes in Scheme 3 for the $X$ $=\mathrm{F}$ and $\mathrm{NMe}_{2}$ systems. The reported relative energies are in $\mathrm{kcal} / \mathrm{mol}$, computed at the B3PW91*-D3 level.

System $3^{\mathrm{x}}$ was only optimized in the quartet state (see Supporting Information). The optimized structures are close to those of the simpler ${ }^{4} 3^{\mathrm{H}}$ model, with long $\mathrm{Fe}-\mathrm{C}$ distances. The Mulliken spin densities are 3.430 on $\mathrm{Fe}$ and -0.520 on $\mathrm{C}$ for ${ }^{4} 3^{\mathrm{F}}$, and 3.402 on $\mathrm{Fe}$ and -0.502 on $\mathrm{C}$ for ${ }^{4} 3^{\mathrm{NMe} 2}$. Consequently, the weak $\mathrm{Fe}-\mathrm{C}$ interaction affords a small energetic stabilization along the OMRP trapping process, probably corresponding to insignificant stabilization on the Gibbs energy scale, for both $X$ substituents (see Figure 8 ). Remember, the Fe-C BDE is likely overestimated after dispersion correction, as discussed above. The CCT intermediates $4^{\mathrm{X}}$ were optimized in all possible spin states, yielding again ${ }^{4} 4^{x}$ as ground state with higher-energy ${ }^{6} 4^{x}$ and ${ }^{2} 4^{x}$. Geometries and relative energies were again close to those of the simpler $4^{\mathrm{H}}$ model (see $\mathrm{SI}$ ). The $\Delta \mathrm{E}(\mathrm{CCT})$, upon taking into account the energies of styrene and of $\mathrm{PhMeCH}^{\circ}$, as well as the dispersion correction, is $25.3(\mathrm{X}=\mathrm{F})$ and $24.9(\mathrm{X}=$ $\mathrm{NMe}_{2}$ ) $\mathrm{kcal} / \mathrm{mol}$ (Figure 8). The nature of $X$ has no significant influence since the bonds being broken and formed do not have a strong ionic component.

So why is the behavior of the $p-\mathrm{F}$ and $p-\mathrm{Me}_{2} \mathrm{~N}$-phenyl derivatives different? The former leads to extensive CCT but the latter, along with the DABP analogue, shows well controlled polymerizations without any CCT. We can draw conclusions once we complete the analysis of the DABP system, which was previously limited to the ATRP/OMRP interplay, ${ }^{[31]}$ with the hydride CCT intermediate. This was restricted to the quartet spin state. The details of this optimized structure, which shows all the expected features on the basis of the above discussed ${ }^{4} 4^{x}$ systems, are also given in the SI. Of importance to the present discussion, $\triangle E(C C T)$ is only $20.8 \mathrm{kcal} / \mathrm{mol}$. The rationalization of the smaller $\triangle E(C C T)$ for the DABP system is the same as for the greater $\triangle \mathrm{E}(\mathrm{ATRP})$ and smaller $\triangle \mathrm{E}(\mathrm{OMRP})$ : the energetic 
destabilization of the ATRP catalyst because of the geometric constraint imposed by the tetradentate ligand. This strain is released equally well in the 5-coordinate geometries of the ATRP trapping species, the OMRP dormant species and the CCT intermediate. The full energetic picture for this system, including the ATRP and OMRP results that have already been reported in our previous study, ${ }^{[31]}$ is presented in Figure 9. In comparison with the a-diimine systems in Figure 8, it is apparent the DABP system in Figure 9 is predicted to have even more facile CCT. The electronic structures are identical for all systems and there is not particular steric encumbrance in the DABP system to generate a significant overbarrier for the $\mathrm{H}$ atom transfer process. The absence of observable CCT for this system, therefore, cannot be related to the $\triangle E(C C T)$ value.

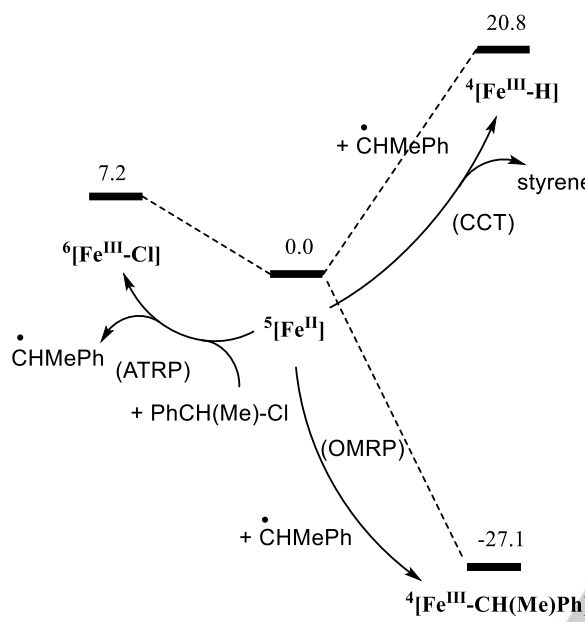

Figure 9. Energy diagram of the interplaying processes in Scheme 3 for the $[\mathrm{Fe}(\mathrm{DABP})]$ ATRP catalyst, which is indicated as ${ }^{5}\left[\mathrm{Fe}^{\mathrm{ll}}\right]$. The reported relative energies are in $\mathrm{kcal} / \mathrm{mol}$, computed at the B3PW91*-D3 level. The energies of the ATRP and OMRP processes are taken from ref. ${ }^{[31]}$.

On the basis of the energetic pictures of Figure 8 and Figure 9 , the observed results can be rationalized on the basis of the relative rate of the controlled chain growth and CCT processes. The activation barrier associated to the controlled growth process corresponds to the thermodynamic ATRP equilibrium plus the activation barrier for the radical addition to monomer. For the two diimine derivatives in Figure 8, the sum of these two terms may well be close to the activation barrier of the CCT process. Given that the barrier to radical propagation is system independent, the chain growth process is predicted to be faster for the $1^{\mathrm{NMe} 2}$ catalyst than for the $1^{\mathrm{F}}$ catalyst, whereas the CCT barrier is essentially the same. The barrier for the chain growth process is even smaller for the DABP system. These relative barrier heights correlate qualitatively with the observed differences in polymerization rate. An additional factor of importance is the more extensive trapping of the ATRP/CCT catalyst for the DABP system to yield the OMRP dormant species. This reduces the effective $\mathrm{Fe}^{\|}$catalyst concentration.

Therefore, the rationalization of the more controlled chain growth for $1^{\text {NMe2 }}$ and for the DABP system is simply that the background CCT process is not sufficiently fast to significantly affect the polymer molecular weights. For the $1^{\mathrm{F}}$ system, on the other hand, the two barriers are closer in energy, leading to a more significant incidence of CCT. Even though CCT appears to be more accessible for the DABP system on an absolute scale, $\triangle \mathrm{E}(\mathrm{ATRP})$ is much smaller and this system also benefits from additional OMRP radical trapping, which further lowers the concentration of both partners needed for the CCT process.

We must stress, once again, that the investigation presented here is not meant to provide thermodynamic parameters of absolute value, even though an effort was made to model the correct ground spin state of all systems through selection of the ad hoc B3PW91* functional and to adjust the estimation of bond dissociation energies by application of a dispersion correction. The rates of the various processes are related to reaction barriers expressed in terms of the Gibbs energy, which is notoriously difficult to estimate for processes occurring in a condensed phase. This study was only meant to provide chemical insight about the mechanisms of the various processes, finding satisfactory answers to the questions laid out in the Introduction. We believe that this task has been accomplished on the basis of a model that has successfully withstood a number of tests and appears self-consistent.

\section{Conclusions}

We have provided the first self-consistent rationalization of a number of experimentally observed phenomena for $\alpha$-diimine iron complexes in metal-mediated radical polymerization. The apparently bizarre behavior of the $\left[\mathrm{FeCl}_{2}(\mathrm{CyN}=\mathrm{C}(\mathrm{Ar})\right.$ $\mathrm{C}(\mathrm{Ar})=\mathrm{NCy})$ ] ATRP catalyst for the radical polymerization of styrene, with controlled chain growth observed when $\mathrm{Ar}=p$ $\mathrm{C}_{6} \mathrm{H}_{4} \mathrm{NMe}_{2}$ and polymerizations affected by CCT when $\mathrm{Ar}=p$ $\mathrm{C}_{6} \mathrm{H}_{4} \mathrm{~F}^{[28,35]}$ does not appear to be related to the ground spin state of the corresponding ATRP radical trapping complex $\left[\mathrm{FeCl}_{3}(\mathrm{CyN}=\mathrm{C}(\mathrm{Ar})-\mathrm{C}(\mathrm{Ar})=\mathrm{NCy})\right]$. Our calculations indicate that all these trichloride complexes adopt a sextet ground state and that the nature of the aryl para substituent has no significant effect on the sextet-quartet gap. The observed behavior is rationalized in terms of a small but significant electronic effect of the phenyl para substituent on the thermodynamic ATRP activation equilibrium as expressed by $\triangle \mathrm{E}(\mathrm{ATRP})$. This makes the overall barrier toward the ATRP activation/monomer addition process much smaller than that leading to CCT, hence the underlying CCT process becomes less important. The same rationalization is also valid for the related [ $\mathrm{Fe}(\mathrm{DABP})]$ catalyst, which promotes a well controlled and very rapid chain growth ${ }^{[23,30]}$ in spite of an even smaller $\triangle \mathrm{E}(\mathrm{CCT})$. [Fe(DABP)] also benefits from a more favorable OMRP trapping, lowering the concentration of both partners needed for the CCT process. Our study has also addressed the intimate details of the CCT mechanism. Contrary to the previous suggestion of CCT being triggered for this system by OMRP trapping followed by $\beta-\mathrm{H}$ elimination, our calculations suggest that CCT can proceed via a direct $\mathrm{H}$-atom transfer from the active radical to the ATRP catalyst, leading to the hydride CCT intermediate without any overbarrier. The 
OMRP dormant species is not sufficiently stabilized for this system, likely present in very small concentrations as an off-loop species. $\beta-\mathrm{H}$ elimination can either proceed along a single state quartet surface or a two-state pathway through an agostic doublet spin isomer, in both cases without the generation of an olefin complex as a stable local minimum. The single state quartet pathway has a smaller energetic barrier, but is still less favorable than the direct $\mathrm{H}$-atom transfer pathway. The considerations outlined in this contribution may be of importance for designing other efficient Fe-based ATRP catalysts and inform the understanding of other one-electron reactions.

\section{Computational details}

The computational work was carried out using the Gaussian09 suite of programs. ${ }^{[53]}$ The geometry optimizations were performed without any symmetry constraint using the B3PW91* functional, a modified version of the B3PW91 functional in which the c3 coefficient in Becke's original three-parameter fit ${ }^{[54]}$ to thermochemical data was changed to 0.15 . The 6-31G basis functions were used for all atoms except $\mathrm{Fe}$ and $\mathrm{Cl}$. The $\mathrm{Cl}$ atom was described with the $6-31 \mathrm{G}(\mathrm{d})$ basis set, whereas the SDD basis set and ECP were used for the Fe atom, augmented by an $f$ polarization function $(\alpha=2.462)$. ${ }^{[5]}$ The $\mathrm{H}$ atom involved in the $\beta-\mathrm{H}$ transfer process was described with the $6-31 \mathrm{G}(\mathrm{d}, \mathrm{p})$ basis set. The MECP calculations were carried out using a code kindly provided by Prof. J. N. Harvey, ${ }^{[56]}$ which interfaced with Gaussian09 to lead the geometry optimization toward the minimum on the seam of crossing between the two PES's of different spin. The unrestricted formulation was used for all open-shell molecules, yielding only minor spin contamination. Maximum deviations for $\left\langle S^{2}\right\rangle$ at convergence were 1.054 (vs. the theoretical value of 0.75 ) for spin doublets, 4.271 (vs. 3.75) for quartets, 6.131 (vs. 6) for quintets and 8.764 (vs. 8.75) for sextets. Corrections for dispersion were carried out at the fixed B3PW91* optimized geometries using Grimme's D3 empirical method (B3PW91*-D3), using SR6 and S8 parameters identical to those optimized for B3PW91. ${ }^{[43]}$ For selected systems, a solvation correction in styrene $(\varepsilon=2.46)$ was carried out by a single point calculation on the optimized gas phase geometry using the SMD polarizable continuum model. ${ }^{[57]}$

\section{Acknowledgements}

This work was granted access to the HPC resources of CINES under the allocation 2014-086343 made by GENCI (Grand Equipement National de Calcul Intensif) and to the resources of the CICT (Centre Interuniversitaire de Calcul de Toulouse, project CALMIP). RP gratefully acknowledges the Centre National de la Recherche Scientifique (CNRS) and the Institut Universitaire de France (IUF) for additional support.

\section{Keywords: Iron • ATRP • OMRP • CCT • DFT calculations}

[1] J.-S. Wang, K. Matyjaszewski, J. Am. Chem. Soc. 1995, 117, 56145615 .

[2] J.-S. Wang, K. Matyjaszewski, Macromolecules 1995, 28, 7901-7910.

[3] M. Kato, M. Kamigaito, M. Sawamoto, T. Higashimura, Macromolecules 1995, 28, 1721-1723.

[4] T. Ando, M. Kato, M. Kamigaito, M. Sawamoto, Macromolecules 1996, 29, 1070-1072.
[5] K. Matyjaszewski, Y. Gnanou, L. Leibler, Macromolecular Engineering: Precise Synthesis, Materials Properties, Applications, Wiley-VCH Verlag $\mathrm{GmbH}, 2007$.

[6] M. Ouchi, T. Terashima, M. Sawamoto, Chem. Rev. 2009, 109, 4963 5050.

[7] F. di Lena, K. Matyjaszewski, Progr. Polym. Sci. 2010, 35, 959-1021

[8] R. Poli, Eur. J. Inorg. Chem. 2011, 1513-1530.

[9] R. Poli, Angew. Chem., Int. Ed. 2006, 45, 5058-5070.

[10] K. M. Smith, W. S. McNeil, A. S. Abd-El-Aziz, Macromol. Chem. Phys. 2010, 211, 10-16.

[11] R. Poli, in Polymer Science: A Comprehensive Reference, Vol. 3 (Eds.: K. Matyjaszewski, M. Möller), Elsevier BV, Amsterdam, 2012, pp. 351 375.

[12] L. E. N. Allan, M. R. Perry, M. P. Shaver, Progr. Polym. Sci. 2012, 37, 127-156.

[13] E. Le Grognec, J. Claverie, R. Poli, J. Am. Chem. Soc. 2001, 123, 9513-9524.

[14] F. Stoffelbach, R. Poli, P. Richard, J. Organometal. Chem. 2002, 663, 269-276.

[15] F. Stoffelbach, R. Poli, S. Maria, P. Richard, J. Organomet. Chem 2007, 692, 3133-3143

[16] W. A. Braunecker, Y. Itami, K. Matyjaszewski, Macromolecules 2005 , 38, 9402-9404.

[17] W. A. Braunecker, W. C. Brown, B. Morelli, W. Tang, R. Poli, K Matyjaszewski, Macromolecules 2007, 40, 8576-8585.

[18] Y. Champouret, U. Baisch, R. Poli, L. Tang, J. L. Conway, K. M. Smith Angew. Chem., Int. Ed. 2008, 47, 6069-6072.

[19] Y. Champouret, K. C. MacLeod, U. Baisch, B. O. Patrick, K. M. Smith R. Poli, Organometallics 2010, 29, 167-176.

[20] Y. Champouret, K. C. MacLeod, K. M. Smith, R. Poli, Organometallics 2010, 29, 3125-3132.

[21] M. P. Shaver, M. E. Hanhan, M. R. Jones, Chem. Commun. 2010, 46 2127-2129.

[22] L. E. N. Allan, E. D. Cross, T. W. Francis-Pranger, M. E. Hanhan, M. R Jones, J. K. Pearson, M. R. Perry, T. Storr, M. P. Shaver, Macromolecules 2011, 44, 4072-4081.

[23] L. E. N. Allan, J. P. MacDonald, A. M. Reckling, C. M. Kozak, M. P Shaver, Macromol. Rapid Comm. 2012, 33, 414-418.

[24] R. Poli, L. E. N. Allan, M. P. Shaver, Prog. Polym. Sci. 2014, 39, 18271845 .

[25] T. Ando, M. Kamigaito, M. Sawamoto, Macromolecules 1997, 30, 4507 4510.

[26] V. C. Gibson, R. K. O'Reilly, W. Reed, D. F. Wass, A. J. P. White, D. J. Williams, Chem. Commun. 2002, 1850-1851.

[27] V. C. Gibson, R. K. O'Reilly, D. F. Wass, A. J. P. White, D. J. Williams, Macromolecules 2003, 36, 2591-2593.

[28] M. P. Shaver, L. E. N. Allan, H. S. Rzepa, V. C. Gibson, Angew. Chem. Int. Ed. Eng. 2006, 45, 1241-1244.

[29] M. P. Shaver, L. E. N. Allan, V. C. Gibson, Organometallics 2007, 26 4725-4730.

[30] L. E. N. Allan, J. P. MacDonald, G. S. Nichol, M. P. Shaver, Macromolecules (Washington, DC, United States) 2014, 47, 1249-1257.

[31] R. Poli, M. P. Shaver, Inorg. Chem. 2014, 53, 7580-7590.

[32] M. P. Johansson, M. Swart, Dalton Trans. 2011, 40, 8419-8428.

[33] J. Halpern, J. P. Maher, J. Am. Chem. Soc. 1965, 87, 5361-5366.

[34] J. Halpern, Acc. Chem. Res. 1970, 3, 386-392.

[35] L. E. N. Allan, M. P. Shaver, A. J. P. White, V. C. Gibson, Inorg. Chem. 2007, 46, 8963-8970.

[36] N. Muresan, C. C. Lu, M. Ghosh, J. C. Peters, M. Abe, L. M. Henling, T. Weyhermoller, E. Bill, K. Wieghardt, Inorg. Chem. 2008, 47, 4579-4590.

[37] Allan, L. E. N.; Gibson, V. C. personal communication, 2014.

[38] O. Salomon, M. Reiher, B. A. Hess, J. Chem. Phys. 2002, 117, 4729 4737

[39] J. Harvey, M. Aschi, Faraday Disc. 2003, 124, 129-143.

[40] J. N. Harvey, R. Poli, Dalton Trans. 2003, 4100-4106. 
[41] J.-L. Carreón-Macedo, J. N. Harvey, J. Am. Chem. Soc. 2004, 126, 5789-5797.

[42] M. Besora, J. L. Carreon-Macedo, A. J. Cowan, M. W. George, J. N. Harvey, P. Portius, K. L. Ronayne, X. Z. Sun, M. Towrie, J. Am. Chem. Soc. 2009, 131, 3583-3592.

[43] S. Grimme, J. Antony, S. Ehrlich, H. Krieg, J. Chem. Phys. 2010, 132

[44] H. Hirao, J. Phys. Chem. A 2011, 115, 9308-9313.

[45] A. W. Addison, T. N. Rao, J. Reedijk, J. Vanrijn, G. C. Verschoor, J. Chem. Soc., Dalton Trans. 1984, 1349-1356.

[46] A. Tabard, P. Cocolios, G. Lagrange, R. Gerardin, J. Hubsch, C. Lecomte, J. Zarembowitch, R. Guilard, Inorg. Chem. 1988, 27, 110-117.

[47] H. S. Muddana, A. T. Fenley, D. L. Mobley, M. K. Gilson, Journal of Computer-Aided Molecular Design 2014, 28, 305-317.

[48] R. Sure, J. Antony, S. Grimme, J. Phys. Chem. B 2014, 118, 3431 3440 .

[49] J. Carlsson, J. Aqvist, J. Phys. Chem. B 2005, 109, 6448-6456.

[50] C. E. Chang, W. Chen, M. K. Gilson, J. Chem. Theory Comput. 2005, 1, 1017-1028.

[51] N. Singh, A. Warshel, J. Phys. Chem. B 2009, 113, 7372-7382.

[52] P. A. Dub, R. Poli, J. Mol. Catal. A 2010, 324, 89-96.

[53] M. J. Frisch, G. W. Trucks, H. B. Schlegel, G. E. Scuseria, M. A. Robb, J. R. Cheeseman, G. Scalmani, V. Barone, B. Mennucci, G. A Petersson, H. Nakatsuji, M. Caricato, X. Li, H. P. Hratchian, A. F.
Izmaylov, J. Bloino, G. Zheng, J. L. Sonnenberg, M. Hada, M. Ehara, K. Toyota, R. Fukuda, J. Hasegawa, M. Ishida, T. Nakajima, Y. Honda, O. Kitao, H. Nakai, T. Vreven, J. Montgomery, J. A., J. E. Peralta, F. Ogliaro, M. Bearpark, J. J. Heyd, E. Brothers, K. N. Kudin, V. N. Staroverov, R. Kobayashi, J. Normand, K. Raghavachari, A. Rendell, J. C. Burant, S. S. Iyengar, J. Tomasi, M. Cossi, N. Rega, N. J. Millam, M. Klene, J. E. Knox, J. B. Cross, V. Bakken, C. Adamo, J. Jaramillo, R. Gomperts, R. E. Stratmann, O. Yazyev, A. J. Austin, R. Cammi, C. Pomelli, J. W. Ochterski, R. L. Martin, K. Morokuma, V. G. Zakrzewski, G. A. Voth, P. Salvador, J. J. Dannenberg, S. Dapprich, A. D. Daniels Ö. Farkas, J. B. Foresman, J. V. Ortiz, J. Cioslowski, D. J. Fox Gaussian 09, Revision D.01, Gaussian, Inc., Wallingford CT, 2009.

[54] A. D. Becke, J. Chem. Phys. 1993, 98, 5648-5652.

[55] A. W. Ehlers, M. Boehme, S. Dapprich, A. Gobbi, A. Hoellwarth, V. Jonas, K. F. Koehler, R. Stegmann, A. Veldkamp, G. Frenking, Chem. Phys. Lett. 1993, 208, 111-114.

[56] J. N. Harvey, M. Aschi, H. Schwarz, W. Koch, Theor. Chem. Acc. 1998 , 99, 95-99.

[57] A. V. Marenich, C. J. Cramer, D. G. Truhlar, J. Phys. Chem. B 2009, $113,6378-6396$

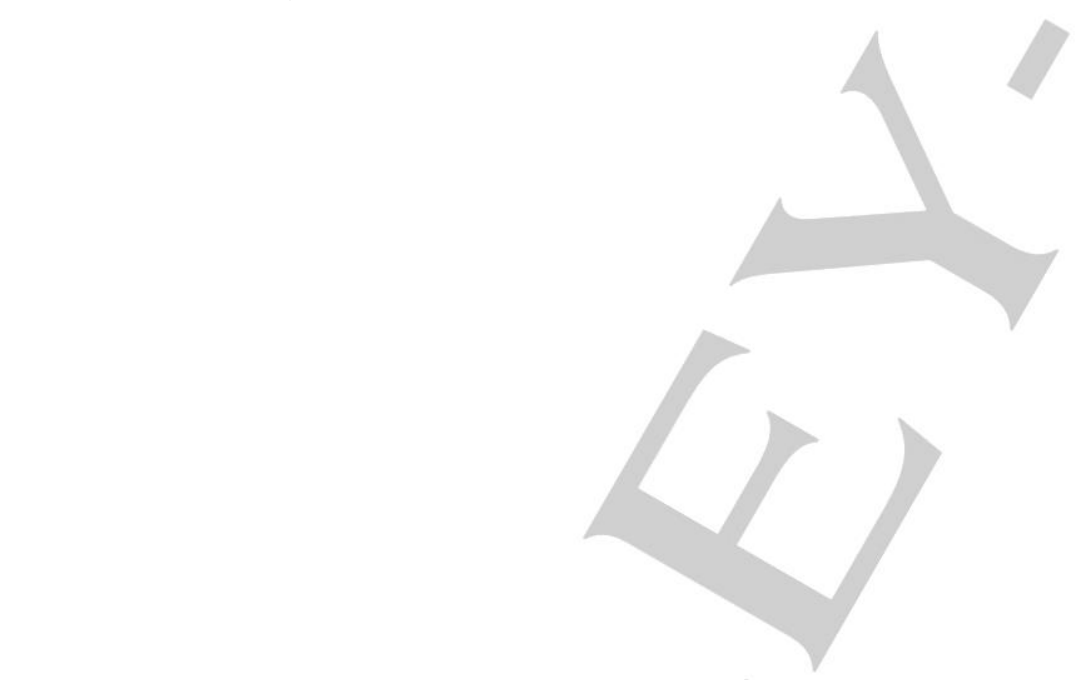




\section{Entry for the Table of Contents}

\section{FULL PAPER}

A DFT study has addressed the ligand influence and the modulating effect of substituents in $\left[\mathrm{FeCl}_{2}\right.$ ( $\alpha$-diimine)] complexes on the interference of catalytic chain transfer in the atom transfer radical polymerization of styrene. The CCT process occurs preferentially via direct $\mathrm{H}$-atom transfer from the radical chain to the metal catalyst, rather than via an organometallic intermediate and $\beta$ hydrogen elimination.

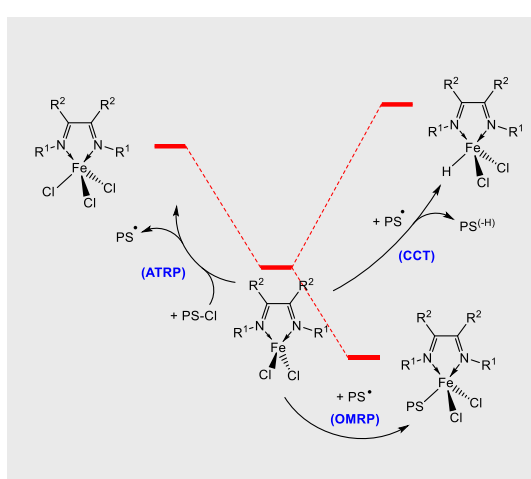

Rinaldo Poli, ${ }^{*}$ Michael P. Shaver

Page No. - Page No.

ATRP/OMRP/CCT Interplay in Styrene Polymerization Mediated by Iron(II) Complexes: a DFT Study of the $\alpha$-Diimine System 